\title{
Hybrid Power Generation System
}

\author{
Gagari Deb, Ramananda Paul, and Sudip Das
}

\begin{abstract}
Combination of different but complementary energy generation systems based on renewable energies or mixed is known as hybrid system. In this paper a hybrid power system is designed with wind energy and hydro power source using PSCAD software. Here a simulation approach is adopted to observe the different characteristics of hybrid power system. From the study it is clear that this hybrid power system provides voltage stability and automatic load sharing capability.
\end{abstract}

Index Terms-Automatic load sharing, hybrid power system, hydro power, wind power, voltage stability.

\section{INTRODUCTION}

Several renewable sources have been through a good development in the last decades. Therefore, their combination would apparently provide a good uninterruptible power system. Different renewable generators would complement each other. However, a lot of requirements have to be considered first. It is important to understand all the factors that influence its behavior, in order to get the best of it. The most important factors are location, time and user needs (power). Location associates information about climate, energy sources availability and environment conditions. This information is very important to decide what kind of renewable generators can be chosen [1].

Again the rapidly increasing costs of power line extensions and fossil fuel, combined with the desire to reduce carbon dioxide emissions pushed the development of hybrid power system suited for remote locations. Hybrid power systems are designed for the generation and use of electrical power. They are independent of a large, centralized electricity grid and incorporate more than one type of power source. They may range in size from relatively large island grids to individual household power supplies. In general a hybrid system might contain alternating current (AC) diesel generators, an AC distribution system, a DC distribution system, loads, renewable power sources, energy storage, power converters, rotary converters, coupled diesel system, dump loads, load management options or a supervisory control system.[2][3].

Manuscript received February 9, 2012; revised March 17, 2012. This work was supported in part by the U.S. Department of Commerce under Grant BS123456 (sponsor and financial support acknowledgment goes here). Paper titles should be written in uppercase and lowercase letters, not all uppercase.

G. Deb is with the National Institute of Standards and Technology, Boulder, CO 80305 USA (e-mail: author@ boulder.nist.gov).

R. Paul is with the Department of Physics, Colorado State University, Fort Collins, CO 80523 USA (e-mail: author@lamar. colostate.edu).

S. Das is with the Electrical Engineering Department, University of Colorado, Boulder, CO 80309 USA, on leave from the National Research Institute for Metals, Tsukuba, Japan (e-mail: author@nrim.go.jp).
One important aspect of wind turbine applications, especially in industrial environment is that wind turbine generates electricity without creating pollution. In addition the generation of electricity using wind turbines is well suited for isolated places with no connections to the outside grid [4].

Systems with hydroelectric generation can use the free stored hydro energy in the system reservoirs to meet demand, thus avoiding fuel expenses with thermal units [5].

This paper presents several aspects that must be taken into consideration at conception and exploitation level of a hybrid system. This hybrid power system has two renewable energy resources, the wind power and the hydropower. Voltage and frequency control has done by the exciter and the governor. A careful selection of the governor parameters can produce a stable and satisfactory operation of the system and respond according to load changes. The analysis includes the performance characteristic of all the generators connected to this system. This model is used to study the different characteristics of power and field voltage. The hybrid power system which is designed based on PSCAD software is representing a sustainable and powerful technological solution to increase access to modern electricity services in rural areas and beyond.

\section{SOURCES OF POWER GENERATION}

The conventional energy sources are limited and have pollution to the environment. For this reason more attention has been paid to the utilization of renewable energy sources such as wind energy, fuel cell and solar energy etc. Wind energy is the fastest growing and most promising renewable energy source. During last two decades, the high penetration of wind turbines in the power system has been closely related to the advancement of the wind turbine technology and the way of how to control. Doubly-fed induction machines are receiving increasing attention for wind energy conversion system during such situation [6].

Wind turbine is classified into two general types: 1 . Horizontal axis and 2.Vertical axis. The limitations on the extraction of energy from the wind include the practical size of wind machines, their density, friction losses in the rotating machinery and efficiencies of conversion from rotational energy to electrical energy. A windmill works on the principle of converting kinetic energy of the wind to rotary mechanical energy. In more advanced model the rotational energy is converted into electricity [7].

Wind turbines convert the kinetic energy present in the wind into mechanical energy by means of producing torque. Since the energy contained by the wind is in the form of kinetic energy, its magnitude depends on the air density and the wind velocity. The wind power developed by the turbine is given by the equation: 


$$
\mathrm{P}=1 / 2 \mathrm{Cp} \rho \mathrm{AV}^{3}
$$

where $C p$ is the Power Co-efficient, $\rho$ is the air density in $\mathrm{Kg} / \mathrm{m}^{3}, \mathrm{~A}$ is the area of the turbine blades in $\mathrm{m}^{2}$, and $\mathrm{V}$ is the wind velocity in $\mathrm{m} / \mathrm{sec}[6]$.

Hydro-electric power stations are generally located in hilly areas where dams can be built conveniently and large water reservoirs can be obtained. In a hydro-electric power station, water head is created by constructing a dam across a river or lake. From the dam, water is led to a water turbine. The water turbine captures the energy in the falling water and changes the hydraulic energy (i.e. product of head and flow of water) into mechanical energy at the turbine shaft. The turbine drives the alternator which converts mechanical energy into electrical energy. Hydro-electric power stations are becoming very popular because the reserves of fuels (i.e. coal and oil) are depleting day by day. They have the added importance for flood control, storage of water for irrigation and water for drinking purposes. The constituents of a hydro-electric plant are hydraulic structures, water turbines and electrical equipment [8].

\section{DESCRIPTION OF THE MODEL}

The hybrid power system under discussion consists of three subsystems: Hydroelectric source, Wind power source and loads. The circuit of the entire system based on the PSCAD software has shown in Fig.1.

In case of wind power generation external wind speed is provided to wind source through a slider. Wind speed is given to the wind turbine which provides the mechanical torque. Here the pitch angle of the wind turbine is controlled by the wind governor. The torque provided by the wind turbine helps to rotate the generator shaft which generates electrical power at a voltage rating of $11 \mathrm{kV}$.

For hydropower generation the hydro governor provide mechanical torque to the synchronous generator through interaction with a corresponding turbine. This torque rotates the generator shaft and produce electrical power at a voltage rating of $13.8 \mathrm{kV}$.

Outputs of wind and hydro are connected in same bus. Voltage rating of the bus is $11 \mathrm{kV}$. As the output voltage rating of the hydro power generator is $13.8 \mathrm{kV}$ a step-down transformer is used to transform $13.8 \mathrm{kV}$ to $11 \mathrm{kV}$.

A fixed load of $2 \mathrm{MW}$ is directly connected to the bus for continuous load analysis and another fixed load is connected to the bus through a logic controlled circuit breaker. Depending upon the load demand both the generator generates useful power. If the load is increased above the power rating of the generator then generator will fail to generate power. Most important thing is that both the generators are contributing to fulfil load demand proportionately. But if one generator is failing to generate power then other generator fulfil the load demand as much as possible which is the very important thing in case of hybrid power system. Also a single line to neutral fault is added to see the system behaviour. To know how much coal is saved by using this system, a coal saver calculator is built. At time of simulation this calculator calculates the amount of coal required to generate same amount of power which will be developed from the hybrid system.

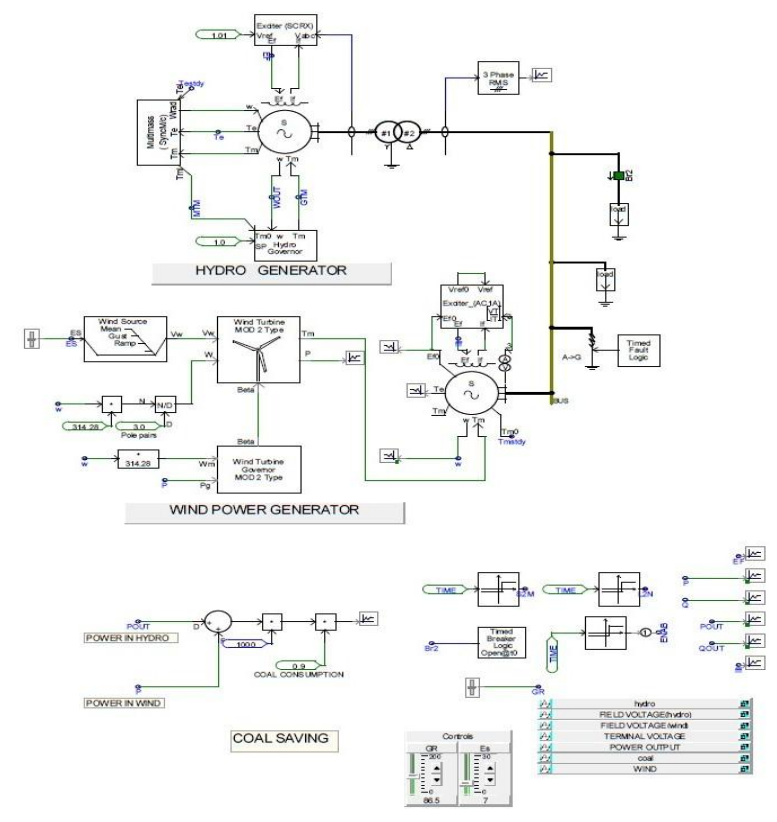

Fig.1. Circuit diagram

\section{ANALYSIS OF THE RESUlTS}

\section{A. Breaker Characteristics}

The breaker control can be configured automatically by using the Timed Breaker Logic component, or the Sequencer components. The breaker may also be controlled manually through the use of on-line controls, or through a more elaborate control scheme. When the breaker logic is 0 , it means breaker is closed and if the breaker logic is 1 then the breaker is open. It can be shown from the graph below.

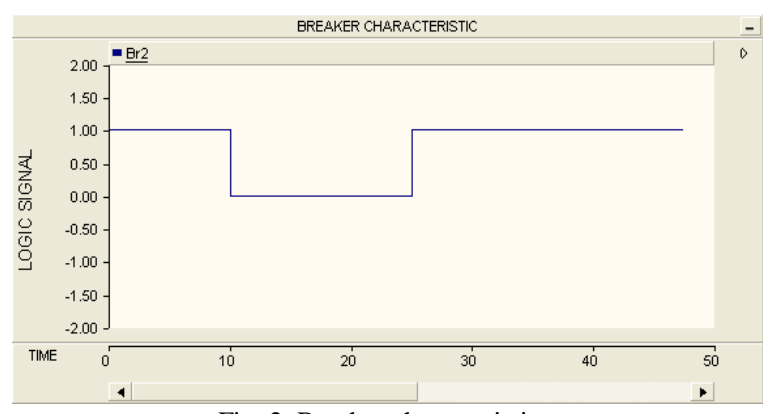

Fig. 2. Breaker characteristics

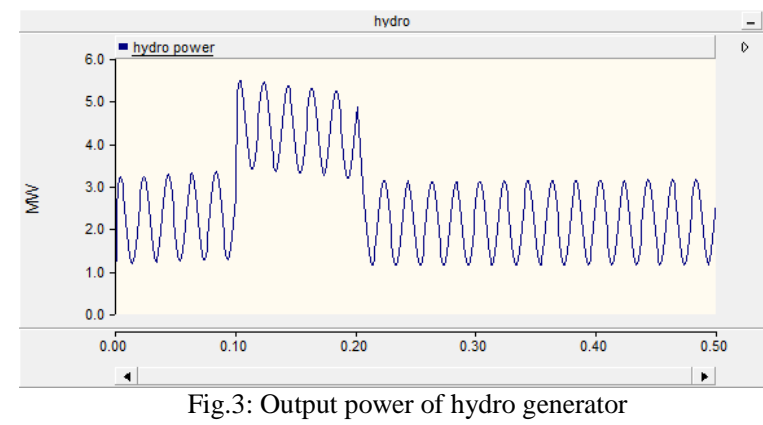

\section{B. Generator Output Curves}

1) When Only Hydro Power Generator is connected: From the graph it is seen that hydro power generator generates power depending upon the load which is connected to the system. But it will change due to load variation in the system. When the load is $3 \mathrm{MW}$ the 
generation of hydro power source is also $3 \mathrm{MW}$ which can be shown from the graph. If another $2 \mathrm{MW}$ fixed load is connected in the system for $0.1 \mathrm{sec}(\mathrm{t}=0.1 \mathrm{sec}$ to $\mathrm{t}=0.2 \mathrm{sec})$ then power output is $5 \mathrm{MW}$ in the interval $\mathrm{t}=0.1 \mathrm{sec}$ to $\mathrm{t}=0.2 \mathrm{sec}$.

2) When Only Wind Power Generator is connected: Wind turbines are self-started depending upon the wind speed. From the graph it is seen that wind power generator generates power depending upon the load which is connected to the system. But it will change due to load demand in the system. When the load is $2 \mathrm{MW}$ the generation of wind power source is $2 \mathrm{MW}$ which can be seen from the graph. If another $2 \mathrm{MW}$ fixed load is connected in the system for $0.1 \mathrm{sec}(\mathrm{t}=0.1 \mathrm{sec}$ to $\mathrm{t}=0.2 \mathrm{sec})$ then the power output from the graph is $4 \mathrm{MW}$.

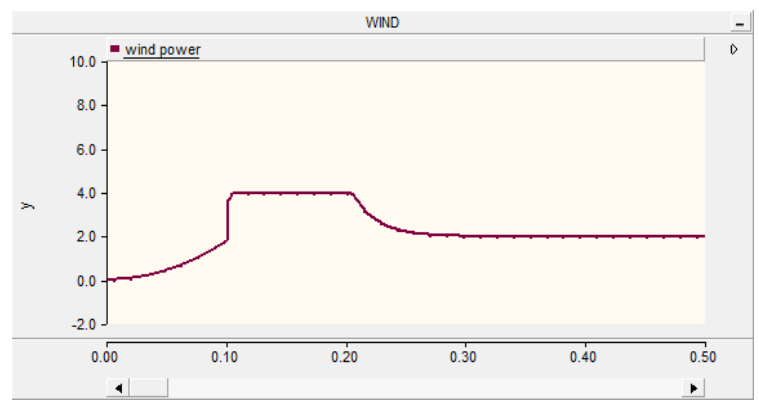

Fig.4: Output power of wind generator

3) Interaction of Wind and Hydro Power Generator: When grid power supply is not available then both the sources generate power and fulfill the customer demand as much as possible. If the load is $2 \mathrm{MW}$ then both the source contributes to fulfill power demand. This will change according to customer demand. When the demand is $4 \mathrm{MW}$ then both the generator shares the demand and generates 4 MW.

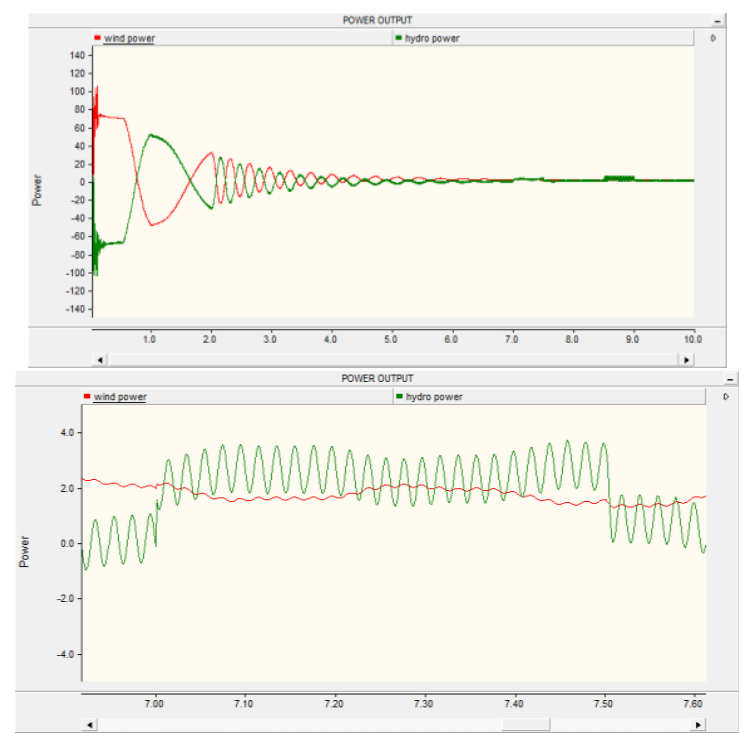

Fig. 5. Output power from both generators

\section{Field Voltage Characteristics}

To investigate the dynamic behavior of a hybrid system during disturbances, a single line- to-ground (SLG) fault is modeled employing the PSCAD fault logic. The fault duration is of $0.3 \mathrm{sec}(\mathrm{t}=7 \mathrm{~s}$ to $\mathrm{t}=7.3 \mathrm{sec})$. The system has returned to the normal operation condition after clearing the fault at $7.3 \mathrm{sec}$. Field voltages acting on both the generators are shown on the graph. It is clearly indicated that the fast change on the field voltage during the fault helps to restore the voltage stability of the system.

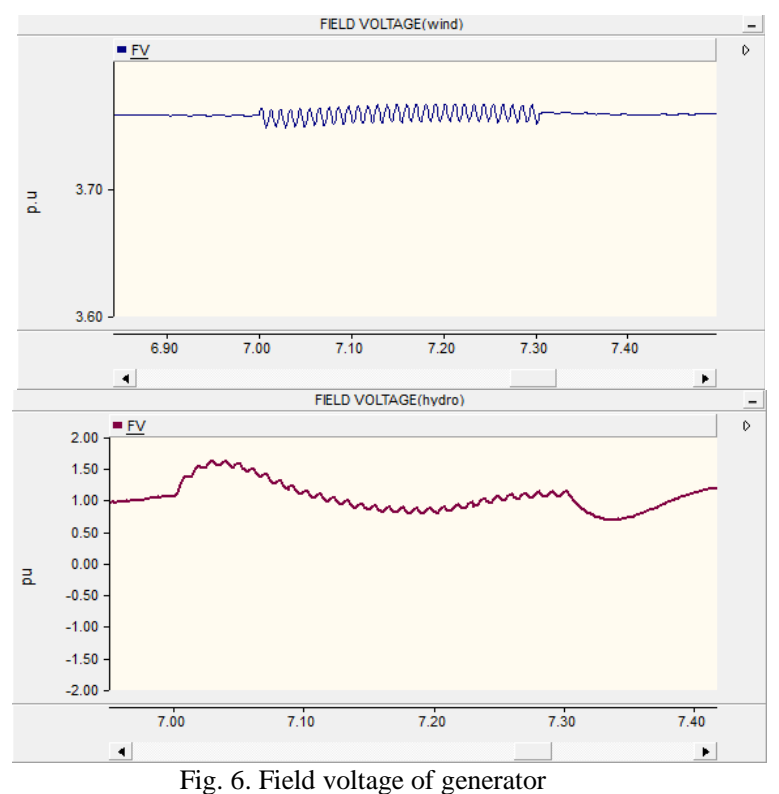

\section{Equivalent Coal Consumption Calculation}

In PSCAD the amount of coal which can be saved through the year can be calculated. This is very much important to use renewal and green energy instead of fossil fuel (coal). The output from the circuit has shown in the graph. The amount of coal is used to produce $10 \mathrm{MW}$ is approximately $592 \mathrm{Kg}$. This is clearly shown in the two graphs.

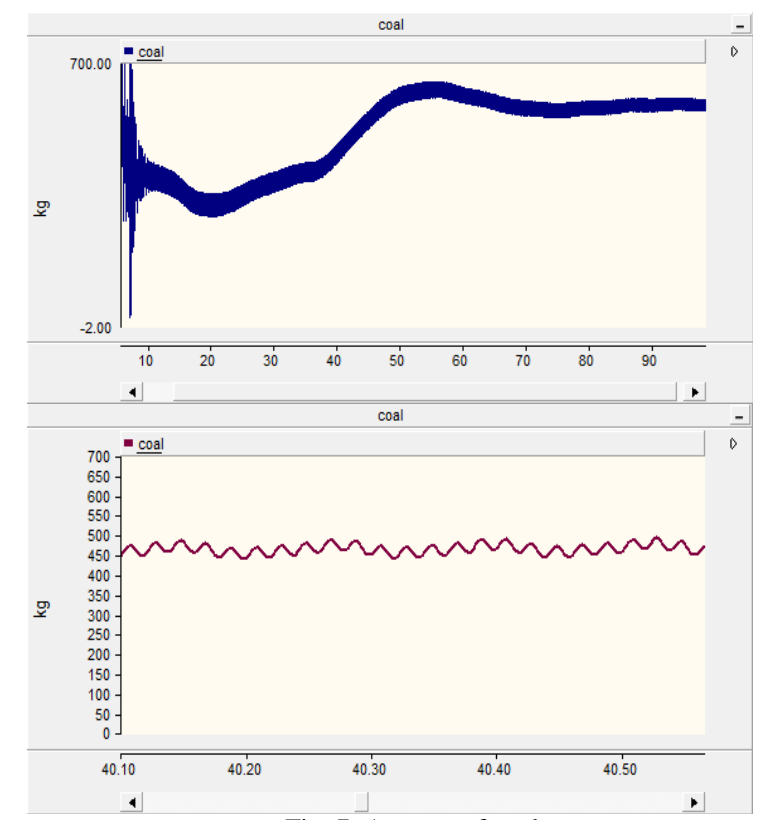

Fig. 7. Amount of coal

\section{DISCUSSION}

When only hydropower generator is connected to the system then it supplies whole power to the load depending upon its capacity. If only wind power generator is connected then power demand will fulfill by it alone. When wind and 
hydro generators work together then due to switching transient power generation fluctuates for some instances but after some time generation of both the generator reaches to stable state. From the combined power graph it is seen that both the generator generates power according to their capacity and fulfill the power demand. In any instance if load demand is increased within the plant capacity then the generators output power changes and they supply power to the load according to their load sharing capacity. If the load is increased beyond the capacity of the system then the generators fail to supply power to the load.

A single-line-to-ground fault is added in the system for some instance. During fault the field voltage will change and system becomes unstable. But the system has returned to the normal operation condition after clearing the fault. In this system, restoration to the normal operating condition after clearing of the fault is faster. This is very clearly shown in the graph. In hybrid power system load demand will fulfill by contribution of all the generators connected to it. It means automatic load sharing occur in case of hybrid power system. If one generator is unable to generate power due to some disturbance then another generator provides the power as much as possible depending upon its capacity.

\section{CONCLUSION}

In this work a hybrid power generation system is designed which shows different characteristics of the system. From the study of the model characteristics it is clear that this hybrid power system provides voltage stability and automatic load sharing capability. For these reasons the system is very much useful to provide good quality of power.

\section{REFERENCES}

[1] E. F. F. Ribeiro, A. J Marques Cardoso, and C. Boccaletti, "Uninterruptible Energy Production in Standalone Power Systems for
Telecommunications," International Conference on Renewable Energies and Power Quality (ICREPQ'09), Valencia (Spain),15 th to 17 th April, 2009.

[2] A. O. Ciuca, I. B. Istrate, and M. Scripcariu, "Hybrid PowerApplication for Tourism in Isolated Areas," World Academy of Science, Engineering and Technology 53 2009, pp. 264-269.

[3] K. Ch. Karasavvas, "Modular Simulation of a Hybrid Power System with Diesel, Photovoltaic Inverter and Wind Turbine Generation," Journal of Engineering Science and Technology Review 1(2008),pp. 38-40.

[4] E. Muljadi and H. E Mckenna, "Power Quality Issues in a Hybrid Power System," IEEE-IAS 2001 Conference Chicago, IIIinois, September 30, 2001-October 4, 2001(To be presented).

[5] E. B. Hreinsson and L. A Barroso, "Defining Optimal Production Capacity in a Purely Hydroelectric power Station," IEEE 2 nd International Conference on Electric Utility Deregulation, Restructuring and Power Technologies (DRPT 2004), April $5^{\text {th }}-8^{\text {th }}$, 2004, HongKong.

[6] B. Chitti Babu and K. B. Mohanty, "Doubly-fed Induction Generator for Variable Speed Wind Energy Conversion Systems-Modeling \& Simulation," International Journal of Computer and Electrical Engineering,Vol.2,No.1,February,2010,1793-8163,pp. 141-147.

[7] S. A. abbasi and Naseema Abbasi, "Renewable Energy Sources and Their Environmental Impact," Prentice Hall of India Private Limited, 2005 , pp.36.

[8] V. K. Mehta, Rohit Mehta, "Principles of Power System," S. Chand and Company Ltd, 2004,pp.17-19.

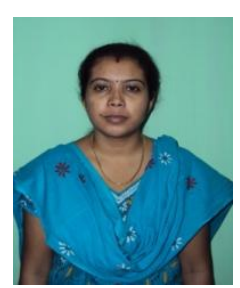

Gagari Deb was born in Tripura on February 24,1982.She has completed her B.E in Electrical Engineering from Tripura Engineering College(now NIT, Agartala) in 2004. She has completed her M.Tech in Electrical Engineering from Tripura University (A Central University) in the year 2008.She is presently working as a LECTURER in Department of Electrical Engineering in Tripura University (A Central University).Her research areas are Energy System, Non-Conventional Energy and Power System etc. Mrs. Deb has published two papers in 2011 International Conference on Electrical Energy and Networks and one paper in National conference on Recent Trends in Alternate Energy 2011. 